\title{
O PAPEL DOS PROFESSORES/EDUCADORES AMBIENTAIS E SEUS ESPAÇOS DE FORMAÇÃO. QUAL É A EDUCAÇÃO AMBIENTAL QUE NOS EMANCIPA?
}

\author{
Laísa Freire ${ }^{1}$ \\ João Figueiredo ${ }^{2}$ \\ Mauro Guimarães ${ }^{3}$
}

\begin{abstract}
Resumo
Neste artigo, sistematizamos as discussões realizadas pelo Grupo de Discussão de Pesquisa Pesquisa em Educação Ambiental (EA) e a Formação de Educadores(as)-Professores(as), no VIII EPEA. Partimos de indagações sobre a formação de professores(as) ${ }^{4}$ e educadores(as) ambientais em EA e sobre o que significa formar um(a) educador(a) ambiental crítico. Construímos eixos de discussão que permitiram a construção coletiva de reflexões sobre os espaços de formação de professores(as)/educadores(as) ambientais e construção de uma identidade; sobre a legitimação de espaços de formação do(a) educador(a) ambiental na universidade e sobre a formação em pesquisa do(a) educador(a) ambiental. Concluímos que um dos caminhos possíveis é a formação crítica e dialógica, que se propõe a reconhecer o(a) educador(a) ambiental em formação como autor(a) de sua própria formação e de sua trajetória como alguém que elabora seu próprio conhecer na relação com outros seres.
\end{abstract}

Palavras-chave: Espaços de formação. Educadores ambientais. Emancipação.

\section{THE ROLE OF ENVIRONMENTAL TEACHERS/EDUCATORS AND TRAINING SPACES. WHAT KIND OF ENVIRONMENTAL EDUCATION COULD PROMOTE EMANCIPATION?}

\begin{abstract}
In this article, we summarize the discussions held during the Discussion Research Group Research in Environmental Education (EE) and the Educators/ Teacher Training in VIII EPEA. We have promoted questions about the training of environmental educator /teacher in $\mathrm{EE}$ and what it means to form a critical environmental educator. We reflected about spaces of training of environmental educator/teacher and his construction of an identity; besides we reflected on the legitimacy of training spaces of environmental educator/teacher at the university and in the research. We conclude that one of the possible ways to training environmental educator/teacher is develop a critical and dialogical training. This one could recognize environmental educator/teacher as an author of his or her own training and his career as someone who draws up its own know in the relationship with other beings.
\end{abstract}

Keywords: Training spaces. Environmental educators. Emancipating.

\footnotetext{
${ }^{1}$ Professora Pesquisadora dos Programas de Educação em Ciências e Saúde (NUTES/UFRJ) e de Ciências Ambientais e Conservação (NUPEM/UFRJ).

2 Professor Pesquisador do Programa de Pós-Graduação em Educação Brasileira (UFC).

${ }^{3}$ Professor Pesquisador do Programa de Pós-Graduação em Educação (UFRRJ).

${ }^{4}$ Os autores do trabalho optaram por utilizar a chamada linguagem não sexista, não necessariamente em acordo com a norma culta da Língua Portuguesa.
} 


\section{EL PAPEL DE LOS PROFESORES/EDUCADORES AMBIENTALES Y SUS ESPACIOS DE FORMACIÓN. ¿QUÉ EDUCACIÓN AMBIENTAL LOGRA EMANCIPARNOS?}

\section{Resumen}

En este artículo se sistematizan las deliberaciones del Grupo de Investigación Pesquisa en Educación Ambiental (EA) y la Formación de Maestros y Educadores, en el VIII EPEA. Partimos de las cuestiones sobre la formación de los docentes ambientales y lo que significa formar un educador ambiental crítico. Hemos construido ejes de discusiones que permitieron la elaboración colectiva de reflexiones sobre las áreas de formación de profesores y educadores ambientales y la construcción de una identidad; sobre la legitimidad de los espacios de formación de los docentes y educadores ambientales en la Universidad y sobre la formación en pesquisa del maestro y del educador ambiental. Llegamos a la conclusión de que una de las posibles maneras de hacerlo es a través de la formación crítica y dialógica, que tiene como objetivo reconocer el educador ambiental en proceso de formación como autor de su formación misma, además de responsable por su trayectoria, como alguien que elabora sus propios conocimientos en la relación con otros seres.

Palabras-clave: Espacios de formación. Educadores ambientales. Emancipación.

\section{Aspectos introdutórios}

A formação de professores(as)/educadores(as) ambientais vem sendo pauta de discussão contínua em vários grupos de trabalho, e é tema de publicações no campo da educação ambiental (EA), como por exemplo Tozoni-Reis (2002), que discute paradigmas que orientam a formação do(a) educador(a) ambiental, e Guimarães (2004), que discute a inserção da dimensão ambiental nas práticas de professores(as), entre outras. Em termos de legislação a inserção da EA na formação inicial docente é regulamentada por políticas públicas como a Política Nacional de Educação Ambiental (PNEA) e as Diretrizes Curriculares Nacionais para a EA (DCN) para a EA. Contudo, as discussões no campo da pesquisa nos levam a refletir sobre as orientações epistemológicas dessa formação.

Dentro das diferentes abordagens da EA que podem orientar a formação do(a) educador(a) ambiental, Layrargues (2006) discute a questão da EA como uma prática pedagógica destinada a alterar ou manter as relações sociais historicamente construídas, e reflete se a EA está reproduzindo ou transformando as condições sociais tal qual se encontram atualmente, se ela reproduz os valores, os princípios, as relações sociais capitalistas ou, ao contrário, se contribui no processo de transformação da realidade socioambiental. O autor afirma que nos espaços centrais do sistema capitalista a concepção de EA que se tornou hegemônica é aquela que tem como tarefa prioritária a promoção de mudanças no comportamento.

Contudo, como diria Morin (1999), seria necessária uma reforma do pensamento, ou uma revolução nas estruturas do próprio pensamento, como contribuição da Educação para a reversão da crise ambiental, de modo a gerar um posicionamento crítico para abranger a dimensão político-ideológica da mudança social que deveria estar mais presente na EA. Outros autores (por ex., LOUREIRO, 2004) vão defender mudanças na estrutura da própria sociedade e no modelo de desenvolvimento societal. Desse modo, a indagação sobre qual é a EA que nos emancipa, proposta no título deste trabalho, se refletida em conjunto com questões da própria formação do(a) educador(a) ambiental, permite trabalhar significados de uma formação comprometida com a superação de relações socioambientais desiguais, percebendo a educação como forma de intervenção no mundo. 
Assim, com este trabalho, pretendemos contribuir para a discussão da formação do(a) educador(a) ambiental, focalizando os resultados de dois dias de discussão no grupo de Pesquisa em EA e a Formação de Educadores-Professores, ocorrido no VIII Encontro Pesquisa em Educação Ambiental (2015). O Grupo de Discussão de Pesquisa (GDP) tinha por volta de 50 pessoas, egressas de diferentes regiões do país e apresentando diversificados modos de relação com a EA, notando-se uma massiva representação de estudantes de pós-graduação e docentes de universidades. As perguntas norteadoras da discussão foram: i. quais as questões significativas para pensar a formação de professores(as) e educadores(as) ambientais na nossa área de trabalho? ii. o que significa formar um(a) educador(a) ambiental crítico(a)?

Por meio dessas questões geradoras, começamos na busca de observações formuladas pelos(as) parceiros(as) do GDP, num sentido mais geral, além da coordenação que ficou a cargo do Mauro Guimarães (UFRRJ), do João Figueiredo (UFC) e da Laísa Freire (UFRJ). Começamos o diálogo em torno de questões geradoras que tinham por propósito potencializar a dialogicidade ao redor da formação de professores(as) e educadores(as) ambientais. Começamos com um tema central, especificamente, sobre as questões significativas para se pensar a formação de professores(as) e educadores(as) ambientais. Nessa vertente, levantando a problemática da formação de um(a) educador(a) ambiental crítico(a).

Nesse movimento, tivemos várias contribuições interessantes e pertinentes. Um dos eixos de reflexão, até por se tratar de um evento de pesquisa em EA, foi buscar um diálogo entre as perguntas norteadoras da discussão e a pesquisa no contexto da formação do(a) educador(a) ambiental. Desse modo, o presente artigo constitui-se de reflexões de seus(suas) autores(as), a partir do relato registrado das intervenções dos participantes do GDP. Assim, nós o organizamos de modo a gerar uma discussão sobre os eixos: Espaços de formação de professores(as) e educadores(as) ambientais e construção de uma identidade; Legitimação de espaços de formação do educador ambiental na universidade como PIBID, programas de Extensão e Grupos de Estudos e Pesquisa e A formação em pesquisa do educador ambiental. $\mathrm{O}$ que nos leva a articular, na discussão, elementos que caracterizam uma formação do(a) educador(a) ambiental que configure processos educativos emancipatórios.

\section{Espaços de formação de professores(as) e educadores(as) ambientais e construção de uma identidade}

Quando nos referimos à questão da identidade de professores(as) e educadores(as) ambientais, partimos do pressuposto de que a construção de uma identidade é possível pelo reconhecimento de que o ser humano é histórico e social e, como tal, tem uma agência que o possibilita interferir e modificar as realidades que o cercam. Essa agência, condiciona e é condicionada pelas diversas estruturas sociais.

A discussão no GDP não problematizou o conceito de identidade, mas o mesmo pareceu-nos tacitamente entendido durante as discussões, como o reconhecimento de uma origem comum ou características de sujeitos que são partilhadas com outros grupos de pessoas ou mesmo a busca de um ideal comum. Desse modo, durante as discussões, a formação da identidade de professores(as) e educadores(as) ambientais foi caracterizada a partir de suas formações acadêmicas (inicial e/ou continuada - na pós-graduação). Por outro lado, cabe mencionar aqui, que do ponto de vista teórico há autores como Hall (2000), Fairclough (2003) que entendem as identidades como um processo de mudança e transformação. Ou seja, as identidades são fragmentadas e não unificadas e, assim, permanecem incessante e multiplamente em processo de construção e reconstrução. Essas questões elucidam alguns limites a esta discussão da identidade do(a) educador(a) ambiental, que apresentamos, neste artigo, como síntese da discussão do grupo. 
A partir da formação que predominantemente observamos no Brasil, a identidade do(a) educador(a) ambiental não vem sendo construída na graduação. Em uma articulação dialógica com o grupo, constatamos que um dos primeiros elementos que cabem na nossa elaboração, se trata de uma formação muito focada na área biológica, que, por conta, das disciplinas estanques que são oferecidas ao longo da graduação, tem uma leitura restrita do campo, desfavorecendo uma percepção mais global. Constatamos que há pouca ou nenhuma discussão sobre as questões ambientais no âmbito das universidades brasileiras. Por outro lado, se questiona porque a formação deveria estar restrita aos espaços universitários.

Durante a discussão no GDP, foram descritos exemplos no Brasil e na Colômbia. A partir dos exemplos, foram observadas diferenças com relação à constituição identitária de professores(as) e educadores(as) ambientais, em ambos os países. Com o aporte de experiências relatadas no nível da graduação, na Colômbia, parece que a identidade de educador(a) ambiental já é trabalhada nos cursos de licenciatura em educação básica, com ênfase em ciências naturais e educação ambiental; ou seja, os egressos da graduação já saem com alguma identidade de educador(a) ambiental.

No exemplo colombiano, a estrutura, ainda que disciplinar, da implantação da EA conta com o apoio de uma legislação, que, até o momento, define e regula essa ênfase no curso. A partir do trabalho de Mejía, Freire e Garcia (2013, s/p), observamos que:

[...] com respeito às disciplinas, se observa que estão divididas em eixos de conhecimento científico, conhecimento pedagógico, conhecimento didático e conhecimento socioambiental. Estes conhecimentos são considerados a nível básico e profissional. [...] as disciplinas com ênfase em EA são profissionais e estão no eixo socioambiental. São sete disciplinas: Cultura da paisagem, História e Educação Ambiental, Problemas Ambientais I e II; Educação Ambiental e Desenvolvimento sustentável e Projeto Ambiental Escolar.

Por outro lado, apesar de termos caracterizado uma proposta de formação do(a) educador(a) ambiental na Colômbia, dentro da área de licenciatura em ciências naturais, há, no Brasil, a preocupação em não restringir essa formação em uma área disciplinar.

A partir de levantamento realizado por Juliani e colaboradores (2014) observamos, na literatura brasileira, uma discussão sobre a inserção da EA na universidade por diferentes modalidades, como através da criação de uma disciplina específica de EA; através de disciplinas afins e/ou por meio de modificações curriculares profundas - ambientalização curricular. Ainda, os trabalhos levantados apontam limites relacionados à polissemia da EA. Segundo Juliani e colaboradores (2014, p.1560) "os cursos de formação docente, ao privilegiarem determinados conteúdos, podem gerar práticas para a manutenção da ideologia dominante e não para a construção de uma EA pautada em diferente racionalidade que não a técnica".

Essa questão também nos traz elementos para se considerar que pensar a formação do(a) educador(a) ambiental e a sua identidade devem ser vislumbradas para além da formação disciplinar do biólogo, geógrafo etc., e que tal formação pode se constituir em espaços alternativos dentro do currículo da própria formação superior, enfoque que exploramos no tópico que se segue. Também, discutimos os espaços de formação na pós-graduação como importantes na constituição de uma identidade do(a) educador(a) ambiental, o que nos remete à relação entre a pesquisa e a formação.

\section{Legitimação de espaços de formação do educador ambiental na universidade como PIBID, programas de Extensão e Grupos de Estudos e Pesquisas}

Entendemos que a formação de um(a) educador(a) ambiental, nesse viés crítico aqui discutido, ultrapassa uma formação teórica cognitiva que deve, também, estar presente nas disciplinas curriculares da formação do licenciado, mas que não deve se restringir apenas a isso, 
como tradicionalmente ocorre. A formação que se acredita necessária para a formação desse(a) educador(a) ambiental, como um sujeito ecológico (CARVALHO, 2004), é a que o(a) potencializa a ser capaz de assumir um papel protagonista no fortalecimento de movimentos contra-hegemônicos na construção de novas relações sustentáveis. É uma formação que se realiza pela práxis, na ação de intervir na realidade, teorizando-a a partir de novos referenciais, em que vivenciar a intencionalidade de novas relações é extremamente pedagógico e educativo para a formação desse sujeito.

Para isso, discutimos diferentes possibilidades de espaços formativos dentro do ambiente acadêmico que temos hoje, não nos restringindo apenas à sala de aula. Logo, ressaltamos a potencialidade do Programa Institucional de Bolsas de Iniciação à Docência (PIBID). Discutimos como um espaço capaz de abrigar esse ambiente educativo de práxis, em que os(as) licenciandos(as) pudessem vivenciar em suas práticas pedagógicas, a realização de novas relações como educadores(as), educandos(as) e cidadãos(ãs) em processos de intervenções nas escolas de sua atuação. Escolas que, encharcadas de realidades vividas de carências, injustiças e degradações socioambientais, apresentam a vida social em sua plenitude e suas contradições. Porém, revelou-se antiga questão: quem forma esses(as) formadores(as) que atuam, hoje, no PIBID? Como sendo a EA uma área recente, ainda em consolidação, consideramos importante indicarmos espaços potenciais que podem ser ocupados pelos(as) educadores(as) ambientais já presentes nas universidades, e o PIBID foi consensualmente indicado.

A realização de projetos de extensão universitária, com participação desses(as) educadores(as) em formação, também foi apontada como um potencial ambiente educativo de práxis pedagógica, por permitir levar o conhecimento acadêmico a interagir com saberes populares, tradicionais, de uma realidade local em que a degradação socioambiental é constitutiva da realidade conflitiva. $\mathrm{O}$ (a) educador(a) em formação terá a possibilidade de, ao levar o conhecimento acadêmico, dialogar com os diferentes saberes em uma relação horizontalizada de uma "ecologia de saberes" (SANTOS, 2007, p.95). Para tanto, essa postura crítica deverá estar presente na intencionalidade do projeto, desde sua concepção, e conduzida pelos(as) professores(as) coordenadores(as) do projeto, comprometidos(as) com essa vertente crítica da EA.

O desenvolvimento dessas ações junto às comunidades requer a ruptura da hegemônica postura de superioridade da academia, que, tradicionalmente, chega como detentora do conhecimento junto aos que não sabem. O exercício da humildade, generosidade, solidariedade e de escuta do(a) outro(a), que, mesmo que esteja em condições de necessidade e carência, tem direito à expressão em pé de igualdade, como reconhecimento do fato de que também são detentores(as) de saberes a serem respeitados. Essa vivência, nesses termos, torna-se condição para estabelecermos posturas dialógicas capazes de construir novas relações nas práticas pedagógicas desenvolvidas por esses projetos de extensão. Isso é extremamente formativo para o(a) educador(a) ambiental crítico(a)!

$\mathrm{O}$ estabelecimento, dentro do espaço acadêmico universitário, de grupos de estudo e pesquisa voltados para as questões ambientais, que reúnam professores(as) pesquisadores(as), pós-graduandos(as), graduandos(as), também foi visto como um potencial ambiente educativo para o exercício dessas relações dialógicas entre seus(suas) participantes. Ressaltamos, ainda, como um espaço que, na contramão da tradição acadêmica hierarquizada e de isolacionismo, pode procurar, no exercício da sinergia da ação conjunta, buscar as brechas nas estruturas tradicionais da vida acadêmica. A participação no fortalecimento dos movimentos contrahegemônicos internos de inserção da ambientalização da Universidade, vivido isso como um grupo, é uma experiência de vivência coletiva de ação conjunta, que tem também grande potencial formativo para esse(a) educador(a) ambiental crítico(a). 


\section{A formação em pesquisa do(a) educador(a) ambiental}

Salientamos que uma das formas de definirmos um caminho seria associar formação e pesquisa na área da EA. A formação é um processo que deve nos envolver. Afinal, nem sempre é necessário mudar o que se faz, mas, sim, mudar como se faz. Nesse ponto, lembramos Paulo Freire, ao problematizar os sentidos que estabelecemos em nossa formação. Para quê? Para quem? A serviço de quem?

Carecemos de reconhecer o quanto estamos defasados(as) em nossa formação ao tratarmos dos dilemas contemporâneos. Quanto identificamos de colonialidade do saber, de subalternização nas práticas de formação que acontecem por aí? Quando falamos de colonialidade, estamos falando de um modelo hegemônico de organização social, que hierarquiza a sociedade de modo tal que o único saber válido é o eurocêntrico, pautado na ciência e na racionalidade cognitivista moderna, pragmática e instrumental, com o intuito de prever e intervir na manutenção da situação social privilegiada pela lógica do capitalismo, do neoliberalismo.

Por isto mesmo é que a ênfase que se tem nas formações, em geral, está associada a uma proposta fragmentada e restrita a procedimentos e práticas circunscritas ao fazer sem maior reflexão, ou ao fazer pontuado na resolução de problemas, sem discussões mais aprofundadas que elenquem causas e alternativas mais radicais para uma sociedade outra, na qual a solidariedade seja o propósito.

Sim, como muitos(as) opinaram, precisamos ter em conta uma formação mais abrangente, que contemple um(a) educador(a) pesquisador(a) criativo(a), crítico(a), dialógico(a) - freireanamente falando - que traga a intencionalidade de colaborar com a partilha de novos meios de aprender na relação e na parceria.

Nessa conjuntura, cabe reconhecer que a ação formadora pode ser pensada dentro de uma lógica de formAção, ou seja, uma pretensão de criar condições de irmos forjando um novo ser mais, fruto de interações críticas e de uma leitura mais ampla da realidade.

A pesquisa nos oferece aportes interessantes ao nos colocar diante do mundo, instigando-nos a avançar nos nossos horizontes de leitura da realidade. Nesse processo de desvelar gradativo, de leituras mais aprofundadas do mundo, vamos nos constituindo seres de maior percepção e, portanto, portadores de leituras e partilhas mais amplas. Como se afirmou no grupo, o ato de pesquisar - principalmente para o(a) pesquisador(a)/educador(a) iniciante vai proporcionar o reconhecimento de que estamos numa busca para além do imediato, para adiante da ideia de tirar da realidade aquilo que se necessita e pronto, numa desconsideração do que está invisível ou envolto nas brumas dos mitos e fantasias socialmente edificadas, ou das lógicas opressoras e excludentes que fomentam a subalternização e a colonialidade, como nós diríamos.

Foi dito, ainda, que o ato de pesquisar implica na necessidade de uma coerência teóricometodológica, marcada por uma formação crítica. Nesse sentido, há de se ter uma intenção crítica no ato de pesquisar, que resulte numa formação crítica do(a) pesquisador(a)-educador(a).

Desconsiderar isso é um ato político, tanto quanto considerar isso implica numa opção política comprometida com uma sociedade democrática e socialmente equânime e ecologicamente responsável. Afinal, precisamos reconhecer o poder que temos como fruto de experiências exitosas que demonstram o potencial desses processos de pesquisa-formação crítica. Nesse rumo, salientamos que mesmo as experiências de insucesso podem ser relevantes na ação de formar, na formação.

Levamos em conta, ainda, o cuidado que precisamos ter ao pensar o(a) professor(a) pesquisador(a) como uma práxis grupal, dissociada da ideia da sociedade moderna que contempla, sempre, o individualismo, até nas propostas de formação. Carecemos de paradigmas de co-laboração, de parcerias, de solidariedade nas ações-reflexões de formação. 
Além disso, entendemos que o ato de pesquisar-formar ocorre em vários contextos e dimensões. Nesse sentido, a sala de aula é um ambiente privilegiado no qual a formaçãopesquisa acontece no antes, no durante e no depois. No antes, ao se preparar uma práxis docente, carecemos de buscar os elementos que podem compor o conteúdo de aula, ainda que na perspectiva dialógica em que se coloca o contexto dos(as) estudantes como um a priori na definição dos temas geradores. Durante, pois que estamos potencializando a curiosidade epistêmica que se faz na pesquisa em torno da resolução das situações-limites elencadas e dialogadas. No depois, ao se verificar o aproveitamento, as fragilidades do processo de ensinoaprendizagem e a futura qualificação da práxis didático-pedagógica.

\section{Considerações finais: em busca de processos educativos emancipatórios}

Neste artigo, os questionamentos que foram trabalhados e discutidos são típicos de uma situação de transição paradigmática. Vislumbrar que a formação desse(a) educador(a) deva ser totalmente diferente daquela já dada é um caminho... Como lidar na tensão entre o ideal e o real?

Para se caminhar na direção de uma formação crítica de educador(a) ambiental crítico(a), faz-se pertinente a luta pela mudança de paradigma. Criticar não implica, necessariamente, em encontrar defeitos e problemas, no aspecto negativo. Porém, atuar criticamente implica, sim, em uma postura atenta e problematizadora, não aceitando passivamente a realidade como dada; assim como, também desvelar o que causa as situações que requerem nossa intervenção e transformação.

Desvelamento do mundo propiciado por uma experiência vivencial - experimentar outras formas de relação onde a amorosidade e a dialogicidade sejam protagonistas - criar processos educativos a partir de situações e condições para que isso possa acontecer. Para isso, nada melhor do que manter vivos os sonhos, as utopias - lugares a se constituir enquanto pontes de interlocução e ação partilhada.

Um dos papéis da EA é a emancipação (deixar de ser ator e ser autor); ou seja, é a possibilidade de sair de mitos e padrões que foram construídos na história da modernidade. Surge então, a questão: como sair de um processo de submissão consentida inconscientemente?

Em uma realidade de crise socioambiental, que sinaliza para uma crise civilizatória, o contexto de transição paradigmática nos faz buscar construir uma identidade de educador(a) ambiental crítico(a). Criamos uma perspectiva de que o ideal é que todo(a) educador(a) seja crítico(a), seja aquele(a) que consegue trazer, para a sua práxis pedagógica, a discussão que emerge da relação ser humano, sociedade e natureza e a degradação das condições de vida, humana e não humana. Se essa perspectiva é trabalhada, pensando que a sua prática contribuiu para a construção do novo, de novas relações socioambientalmente sustentáveis, está se constituindo como um(a) educador(a) ambiental crítico(a). Em uma situação de transição, se acentua o embate pela manutenção do que é - status quo, para aqueles(as) que assumem posturas diferentes das que aí estão. Nesse contexto, a construção da identidade de educador(a) ambiental crítico(a) passa por afirmar uma postura e marcar uma posição.

No processo formativo, as relações são fundamentais para serem trabalhadas. Pensar a transformação do mundo é pensar a transformação das relações no mundo. A realidade hegemônica é verticalizada e gera situações de opressão, degradação, que, por sua vez, geram a crise socioambiental. No mundo que está estruturado dessa forma, o processo formativo deve se dar e ocorrer a partir de relações dialógicas, vivenciando o mundo e a vida... nossa relação com os outros, não só humanos, com a vida. Que a horizontalidade seja estruturante como uma nova forma de ser humano nesta vida que estamos vivendo. Essa outra forma de ser humano nesse processo formativo, propicia que todos(as) nós estejamos nos formando.

Essa formação crítica potencializa que, na ação refletida, nos formemos e participemos no processo formativo de outros. Um dos caminhos possíveis é a formação dialógica, que se 
propõe a reconhecer o(a) educador(a) ambiental em formação como autor(a) de sua própria formação e de sua trajetória, como alguém que elabora seu próprio conhecer na relação com outros seres. Para tanto, nos tornamos dialógicos(as). Salientamos que, para ser dialógicos(as), carecemos de nos tornar dialógicos(as), o que implica em incorporar os princípios fundamentais da dialogicidade, que são: a amorosidade, a fé no ser humano, na esperança ontológica que nos faz mais; na humildade, que reconhece o quanto ainda temos que aprender, e na criticidade, que nos leva adiante nesse processo de desvelar o mundo e com isso ser mais. $\mathrm{O}$ (a) educador(a) dialógico(a) é um(a) educador(a) ambiental.

Diríamos, ainda, que no processo formativo dialógico, algo fundamental é trabalhar novas relações que conscientemente procuram superar o padrão relacional de dominação/ exploração da sociedade moderna. Buscar a transformação do mundo, transcender essa realidade de opressão atual por meio de relações dialógicas que se dão na horizontalidade, na parceria, na partilha cultural.

Como síntese e encaminhamentos possíveis no âmbito das discussões realizadas, entendemos que reconhecer os nossos limites é fundamental. O diálogo não é algo espontâneo, o primeiro pressuposto para o diálogo é reconhecer e buscar o(a) outro(a), o segundo é se postar humildemente, generoso(a) e solidário(a) na relação. Que o diálogo continue...

\section{Agradecimentos}

Gostaríamos de agradecer a todos os participantes do Grupo de Discussão de Pesquisa - Pesquisa em Educação Ambiental (EA) e a Formação de Educadores-Professores, no VIII EPEA, em 2015, que expuseram suas questões e permitiram o estabelecimento de trocas e momentos de aprendizagem, possibilitando as reflexões apresentadas neste artigo. São eles: Maria Bernadete Carvalho, Maria da Conceição do Reis Leal, Regina Helena Munhoz, Stefania Rosa, Shana do N. Silva, Marcia R., Sandra Maria C. Miller, Karina B., Maria L. F. Santos, Fransciso José P., Cristiane Cavalcante, Carolina Alves G. de Oliveira, Bianca Sarpa Miceli, Gladis Slonski, Elizabeth P, Hugo da Silva, Meimilany G, Viviana Orejuella, María Angélica Mejía, Suelen Matoso Couto, Jairo Andrade Velasques, Marcia La Flores, Carlos Antônio, Dalva M. B. Bonotto, Gabriela Rodrigues, Elaine Aparecida, Jandira Talamoni, Helena M. Silva Santos, Leandra Fernandes Alves, Leticia Freitas Azevedo, Marco Polo L. Pres, Evandro Cruz, Noeli B., Vanessa Karine Azevedo, Pedro Vargas, Kleber Vilaça, Tainá Figueiroa, Elizabeth Cristina Ramos Correa, Lucas Quintanilha, William Rocha, Mônica Andrade Modesto, Sama de Freitas Juliani, Lúcia Jobu, Maria Cristina Ferreira do Santos, Thiago leite de Melo, Carolina Mendes, Sueli Polidoro Campos, Marcia Cristina, Paulo B.L de Castro, Felipe Rabelo, Raquel, Tatiana Novaes de Oliveira, Mariana N., Natalia Tavares, Thiago Leite de Mello Ruffo, Roberta Oliveira de Araújo, Cecília Santos de Oliveira.

\section{Referências}

CARVALHO, I. C. M. Educação Ambiental: a formação do sujeito ecológico. São Paulo: Cortez, 2004. [Coleção Docência em Formação].

GUIMARÃES, M. A formação de educadores ambientais. São Paulo: Papirus, 2004. [Coleção Papirus Educação].

HALL, S. Quem precisa de identidade? In: SILVA, T. T. (Org.). Identidade e diferença: a perspectiva dos estudos culturais. Petrópolis: Vozes, 2000. p.103-133

FAIRCLOUGH, N. Analysing Discourse: textual analysis for social research. Abingdon: Routledge, 2003. 
JULIANI, S. F. ; FREIRE, L.M. ; GARCIA, E. ; REZENDE FILHO, L. A. C. Inserção da Educação Ambiental na formação inicial docente: levantamento de publicações. Rev. Tecné, Episteme y Didaxis, Bogotá, v. NE, p.1555-1562, 2014.

LAYRARGUES, P. P. Além da Natureza: Educação Ambiental e Reprodução Social. In LOUREIRO, C. F. B. LAYRARGUES, P. P.; CASTRO, R. (Orgs.). Pensamento Complexo, Dialética e Educação Ambiental. São Paulo: Cortez, 2006.

LOUREIRO, C. F. B. Educação Ambiental Transformadora. In: LAYRARGUES, P.P. (Org.). Identidades da Educação Ambiental Brasileira. Brasília: Ministério do Meio Ambiente, 2004. p. 6584 .

MEJÍA, A. ; FREIRE, L.M.; GARCIA, E. . La educación ambiental en la formación inicial de profesores de ciencias: un estudio de caso en la universidad del Valle, Colombia. In: ENCONTRO NACIONAL DE PESQUISA EM ENSINO DE CIÊNCIAS, 9, 2013, Águas de Lindóia. Anais eletrônicos... Aguas de Lindóia: ABRAPEC., 2013. Disponível em: < http://www.nutes.ufrj.br/abrapec/ixenpec/atas/resumos/R0784-1.pdf>, 2013. Acesso em: 31 ago. 2016.

MORIN, E. Ciência com Consciência. 3 ed. Tradução de: ALEXANDRE, M.D. ; DÓRIA, M.A.S. Rio de Janeiro: Bertrand Brasil, 1999.

SANTOS, B. de S. Para além do pensamento abissal: das linhas globais a uma ecologia de saberes. Novos estud. - CEBRAP, São Paulo, v. 27., n.79, p.71-94, Nov. 2007.

TOZONI-REIS, M. F. C. Formação de Educadores ambientais e paradigmas em transição. Ciência \& Educação, Bauru, v.8, n.1, p.83-96, 2002. 